\title{
EVALUATION OF ANTI-TYROSINASE ACTIVITY OF ALLIUM URSINUM EXTRACTS AND THEIR METAL COMPLEXES
}

\author{
Mohammad Nikkhahi ${ }^{1}$, Effat Souri ${ }^{1}$, Parisa Sarkhail ${ }^{\varpi}$, Maryam Baeeri², \\ Negar Mohammadhosseini² \\ ${ }^{1}$ Department of Medicinal Chemistry, Faculty of Pharmacy, Tehran University of Medical Sciences (TUMS) \\ Tehran, Iran \\ ${ }^{2}$ Pharmaceutical Sciences Research Center (PSRC), The Institute of Pharmaceutical Sciences (TIPS), Tehran University of Medical \\ Sciences (TUMS), Poursina Av., PO Box 14155-6451, Tehran, Iran
}

\begin{abstract}
Background. A. ursinum is found to contain high levels of some beneficial phenolic and poly phenolic compounds were found to be effective in scavenging DPPH radicals and tyroinase inhibition. The aim of this study was to evaluate the anti-tyrosinase and antioxidant activity of three different extracts from the ultrasound-assisted method and their metal complexes from $A$. ursinum to discover new candidates for food additives, cosmetic and pharmaceutical products.

Material and methods. Water, $70 \%$ ethanol and absolute ethanol extract of Allium ursinum and their manganese and zinc-complexes were characterized by FT-IR and UV-Vis spectra and their antioxidant and antityrosinase activity determined using DPPH radical scavenging and mushroom tyrosinase assay.

Results. The antioxidant activity of the water extract was superior to other samples, while the $70 \%$ ethanol extract exhibited the highest anti-tyrosinase activity. Metal complex formation of the extracts led to a significantly lower antioxidant effect. The tyrosinase inhibition strongly related to the metal ion and extraction solvent. All the zinc complexes had lower anti-tyrosinase activity than their extracts, while the manganese complex of the water and absolute ethanol extracts exhibited higher anti-tyrosinase activity than related extracts. Conclusion. This study shows that Mn complex of A. ursinum extracts, based on the solvent extraction, could increase tyrosinase inhibition activity and could be a good candidate for intended cosmetic applications and food additives.
\end{abstract}

Keywords: Allium ursinum, antioxidant, anti-tyrosinase, metal complex, phenolic compounds

\section{INTRODUCTION}

Allium ursinum L. (Ramson or wild garlic) is a perennial herbaceous belongs to Amaryllidaceae family. It grows widely in most regions of Europe, and the north and west of Asia. Ramson's active growing period starts in around early March and continues until June. A. ursinum have been used for years as both a food and a medicinal herb. In European traditional medicine, it is commonly used to help digestion, prevent

All authors declare all sources of funding received for the research submitted to the journal.

This work was part of a Pham D thesis supported by a grant from the Tehran University of Medical Sciences with no. 8911266094: Evaluation of anti-tyrosinase activity of Allium ursinum extracts and their metal complexes. 
cardiovascular disorders, detoxify the body, treat respiratory problems, skin diseases and wound healing, and also for its antimicrobial effects (Sobolewska et al., 2015). Different pharmacological effects of $A$. ursinum have been reported, including anticoagulation, reduction of blood pressure and blood cholesterol, antimicrobial effect, alpha-amylase inhibition, and also antioxidant activity (Bazzaz et al., 2008; Chudzik et al., 2010; Nickavar and Yousefian, 2009). Like other Allium species, sulfur-containing compounds are a major group of $A$. ursinum's chemical composition. These compounds and their precursors from enzymathic decomposition are involved in many biological actions. Cysteine sulfoxides, thiosulfinates and polysulfides are extracted from this plant using different extraction methods. In addition, some steroidal glycosides, flavonoids, phenolic acid, lectins, fructans, fatty acids, amino acids, and also adenosine have been identified in A. ursinum (Sobolewska et al., 2015). A. ursinum is found to contain high levels of some beneficial phenolics, such as gallic acid, $p$-coumaric acid, ferulic acid and flavonoids (Vlase et al., 2013). Lachowicz et al. (2017) confirmed the leaves of A. ursinum have more pheonolic content than other parts of the plant. Many studies explained that (poly) phenolic compounds such as flavonoids have an important role in many bioactive actions and metal complexes of these have various interesting properties, including anti- or pro-oxidant, anti-proliferative and antimicrobial activity (Kasprzak et al., 2015).

Tyrosinase enzyme, a copper-containing multifunctional oxidase, is responsible for skin pigmentation and enzymatic browning in food products. Tyrosinase catalyzes the rate-limiting steps in melanin synthesis: the hydroxylation of tyrosine to dihydroxyphenylalanine (DOPA) by monophenolase activity and the oxidation of DOPA to dopaquinone by diphenolase activity. The overproduction of melanin may cause various hyperpigmentation disorders, such as melasma, solar lentigo, and age spots (Briganti et al., 2003). Previous reports explained that the tyrosinase inhibitors can act via hydroxyl groups which bind to the copper in the active site of tyrosinase, resulting in a conformational change or steric obstruction of the binding (Saewan et al., 2011). On the other hand, many studies indicated that different antioxidant activity of flavonoids is due to the number and position of hydroxyl and glycoside groups in their structure (Bukhari et al., 2009; Zhou et al., 2001). The most common flavonoids found in this species are kaempferol derivatives (Oszmiański et al., 2013). Kaempferol was found to be effective as a flavonol in scavenging DPPH radicals (Li et al., 2004). Additionally, kaempferol and some other isolated compounds from A. ursinum such as gallic acid exhibited anti-tyrosinase activities (Kim, 2007; Rho et al., 2011). Some recent studies confirmed that the stability and biological activity of a number of phenolic compounds improved after metal complex formation. For example, curcumin complexation with some metal ions such as $\mathrm{Cu}(\mathrm{II}), \mathrm{Zn}(\mathrm{II}), \mathrm{Mg}(\mathrm{II})$, and $\mathrm{Mn}(\mathrm{II})$ enhanced DPPH the radical scavenging effect and ferrous reducing power activity in comparison with free curcumin (Thakam and Saewan, 2011). Furthermore, curcumin-Mn and - Zn complexes showed greater anti-tyrosinase activity when compared with free curcumin, whereas it was reduced in $\mathrm{Cu}(\mathrm{II}), \mathrm{Fe}(\mathrm{II})$ and $\mathrm{Mg}(\mathrm{II})$ complexes with curcumin (Saewan et al., 2014). The chelation of two flavonoids, rutin and epicatechin, with $\mathrm{Fe}(\mathrm{II}), \mathrm{Cu}(\mathrm{II})$ and $\mathrm{Zn}(\mathrm{II})$ was found to be more effective in DPPH radical scavenging than the free flavonoids (Symonowicz and Kolanek, 2012). Ultrasound-assisted extraction was shown in previous studies to be a suitable and economical method for the extraction of total phenolic compounds (Figueiras et al., 2017).

To the best of our knowledge, the anti-tyrosinase activity of this species has not yet been described. Therefore, the present study was undertaken to evaluate the antioxidant and anti-tyrosinase activity of three different extracts from the ultrasound-assisted method and their metal complexes from A. ursinum to discover new candidates for food additives, cosmetic and pharmaceutical products.

\section{MATERIALS AND METHODS}

\section{Chemicals}

Folin-Ciocalteu (FC) reagent, 2,2-diphenyl-1-picryl -hydrazyl (DPPH), kojic acid, mushroom tyrosinase and sodium carbonate anhydrous, and gallic acid were purchased from Sigma-Aldrich (Sternheim, Germany). Other chemicals and solvents were obtained from Merck (Darmstadt, Germany). 


\section{Preparation of plant extracts}

Aerial parts of Allium ursinum (Amaryllidaceae) were bought at a Tehran local supermarket and identified by the corresponding author. The leaves were washed and cut into small pieces $\left(1 \mathrm{~cm}^{2}\right)$. The $100 \mathrm{~g}$ of fresh plant was extracted separately with $300 \mathrm{~mL}$ of water $(100 \%)$, ethanol $(70 \%)$ and ethanol $(100 \%)$ using an ultrasonic water bath (Tecno-Gaz Tecna 6) for $60 \mathrm{~min}$ at $40^{\circ} \mathrm{C}$. The mixtures were then centrifuged $(4000$ $\mathrm{rpm}, 25^{\circ} \mathrm{C}$ ) for $20 \mathrm{~min}$ and supernatants were filtered through Whatman paper no. 1. After evaporating the ethanol solvent under a vacuum, the aqueous residue was removed with a freeze-dryer. All dried extracts were weighed to determine the extraction yield and kept at $4^{\circ} \mathrm{C}$ prior for experimental studies.

\section{Determination of total phenolic content}

The total phenolic content in each extract was determined according to the Folin-Ciocalteu method explained by Sarkhail et al. (2017). The amount of total phenolic content in the samples was expressed as a gallic acid equivalent from a calibration curve. The results were expressed as milligrams of gallic acid (GA) equivalents per gram of the fresh plant.

\section{Preparation of metal complexes}

The metal complexes of A. ursinum extracts were prepared by adding the methanol solution of the extract to each metal compound (zinc II acetate $\left(\mathrm{Zn}\left(\mathrm{CH}_{3} \mathrm{COO}\right)_{2}\right)$, manganese (II) chloride $\left(\mathrm{MnCl}_{2}\right)$ ) in a weight ratio of $1: 1$ and the $\mathrm{pH}$ was adjusted to 7-8 with a sodium hydroxide solution. The mixture was refluxed in an oil bath with magnetic stirring for $3 \mathrm{~h}$ at $60^{\circ} \mathrm{C}$. The resulting solutions were allowed to cool and were then filtered. The filtrate was evaporated on a rotary evaporator and dried under a vacuum at $40^{\circ} \mathrm{C}$ (Kumar and Pandey, 2013).

\section{UV absorption spectrum}

The absorption spectra of $A$. ursinum extracts and their metal complexes (solvent: DMSO:MeOH, 2:1) were obtained at a wavelength of $200-800 \mathrm{~nm}$ using a Shimadzu UV-160A.

\section{FT-IR spectroscopy}

FT-IR spectra of $A$. ursinum extracts and their metal complexes were performed on Nicolet Magna 550-IR by a $\mathrm{KBr}$ pellet technique and the spectra were obtained in the range of $4000-400 \mathrm{~cm}^{-1}$.

\section{Evaluation of DPPH radical scavenging activity}

The scavenging DPPH radical activity of the extracts and metal-complexes were evaluated based on a previously reported method Sarkhail et al. (2017), with different concentrations $(0.25-0.75 \mathrm{mg} / \mathrm{mL})$ of the test samples in DMSO:MeOH, (2:1). The absorbance was recorded at $517 \mathrm{~nm}$ using an ELISA reader. Ascorbic acid was used as the positive control. A dose response curve was plotted to determine the $\mathrm{SC}_{50}$ values. $\mathrm{SC}_{50}$ is defined as the concentration of sample which is sufficient for $50 \%$ of a maximum scavenging activity.

\section{Evaluation of tyrosinase inhibitory activity}

Tyrosinase inhibitory activity was determined according to a procedure explained previously by Sarkhail et al. (2017). Stock solutions $(1 \mathrm{mg} / \mathrm{mL})$ of the extracts and metal-complexes were prepared in DMSO/MeOH (2:1). A mixture of mushroom tyrosinase solution and different concentrations $(0.14-0.71 \mathrm{mg} / \mathrm{mL})$ of the samples or kojic acid (positive control) was pre-incubated at room temperature for $10 \mathrm{~min}$. in triplicate. After that, a reaction was performed by adding L-tyrosine to the mixture. The level of dopachrome formation was measured at $475 \mathrm{~nm}$ after $30 \mathrm{~min}$. using an ELISA reader. The anti-tyrosinase activity expressed as the half maximal inhibitory concentration for each sample ( $\mathrm{IC}_{50}$ values).

\section{Statistical analysis}

All data were expressed as means \pm standard error of mean (SEM) of three replicate determinations. One way analysis of variance (ANOVA) and Tukey's test were used to determine the differences among the means. $P$ values $<0.05$ were regarded as significant.

\section{RESULTS AND DISCUSSION}

\section{Yield of extraction and complex preparation}

The yield of water, $70 \%$ ethanol and $100 \%$ ethanol extracts from A. ursinum were 12.2, 13.6 and $10.6 \%$ of fresh leaves, respectively. The yield percent was calculated based on the weight of complexes and decreased in order; water-Mn $(98.5 \%)>$ ethanol-Zn $(93.3 \%)>$ $70 \%$ ethanol-Zn $(90.3 \%)>$ ethanol-Mn $(89.3 \%)>$ $70 \%$ ethanol-Zn $(85.6 \%)>$ water-Zn $(82.8 \%)$.

\section{UV-Vis spectrophotometric analysis}

The UV-Vis spectra of the extracts displayed a maximum absorption band (II) at about $264 \mathrm{~nm}$ and a weak 
band (I) at $346 \mathrm{~nm}$. As the sulfur compounds from $\mathrm{Al}$ lium spp. showed the maximum absorption in 220-250 $\mathrm{nm}$, it can be suggested that these compounds were decomposed during the extraction process. On the other hand, these data strongly propose that the spectra can be due to flavonoid derivatives. Previous studies confirmed that the most common flavonoid group found in this species is flavonol derivatives (Sobolewska et al., 2015). As a general rule, band I is considered to be associated with absorption (usually $300-380 \mathrm{~nm}$ ) due to the cinnamoyl system (B-ring), and band II with absorption (usually $240-280 \mathrm{~nm}$ ) involving the benzoyl system (A-ring) (Kumar and Pandey, 2013). The UV-Vis spectrum of the metal complex extracts showed the maximum absorption spectra of $\mathrm{Zn}$ (II) complexes of the extracts shifted to the higher wavelength region (about 7-10 nm, bathochromic shift) and the peak at about $346 \mathrm{~nm}$ was not shifted. Among the UV-Vis spectra of Mn(II) complexes, only the water-Mn complex showed a slight increase in band (II; about $4 \mathrm{~nm}$ ). Characteristic absorption of metal (II) ions was related to the $\pi \rightarrow \pi^{*}$ transition that shaped a condensed ring with flavonoids via the 3-hydroxy and 4-oxo groups (band I), or 5-hydroxy and 4-oxo groups (band II). In the present study, the UV-Vis absorption Zn(II) complexes spectra indicated that 5-hydroxy and 4-carbonyl group in the $\mathrm{C}$ ring were involved in this reaction and these results are in agreement with the results of other researchers (Souza and Giovani, 2005). However, Mn-complexes of ethanol (70\%) and absolute ethanol may be formed with other compounds such as carbohydrates and other phenolic compounds.

\section{IR spectrophotometric analysis}

FT-IR spectrum data of the extracts of A. ursinum and their $\mathrm{Zn}$ (II) and $\mathrm{Mn}$ (II) complexes are compared separately in Table 1 and the spectra are shown in Figures $1-3$.

In the extracts, absorption of around $3000-3500 \mathrm{~cm}^{-1}$ can be due to phenolic hydroxyl that involves strong intramolecular hydrogen bonding. In the IR spectra of $\mathrm{Zn}$ and $\mathrm{Mn}$ complexes of the ethanol extract, this band was significantly broader and shifted to a higher frequency $\left(3700 \mathrm{~cm}^{-1}\right)$, demonstrating the presence of water in the complex structures. In the extracts, two small bands present in the 2850 to $2950 \mathrm{~cm}^{-1}$ region correspond to the stretching vibration $v(\mathrm{C}-\mathrm{H})$, while in the IR spectra of the ethanol- $\mathrm{Zn}$ and $-\mathrm{Mn}$ complexes, the $\mathrm{v}(\mathrm{C}-\mathrm{H})$ bands are affected by the overlapping of water molecules in the complexes' structure.

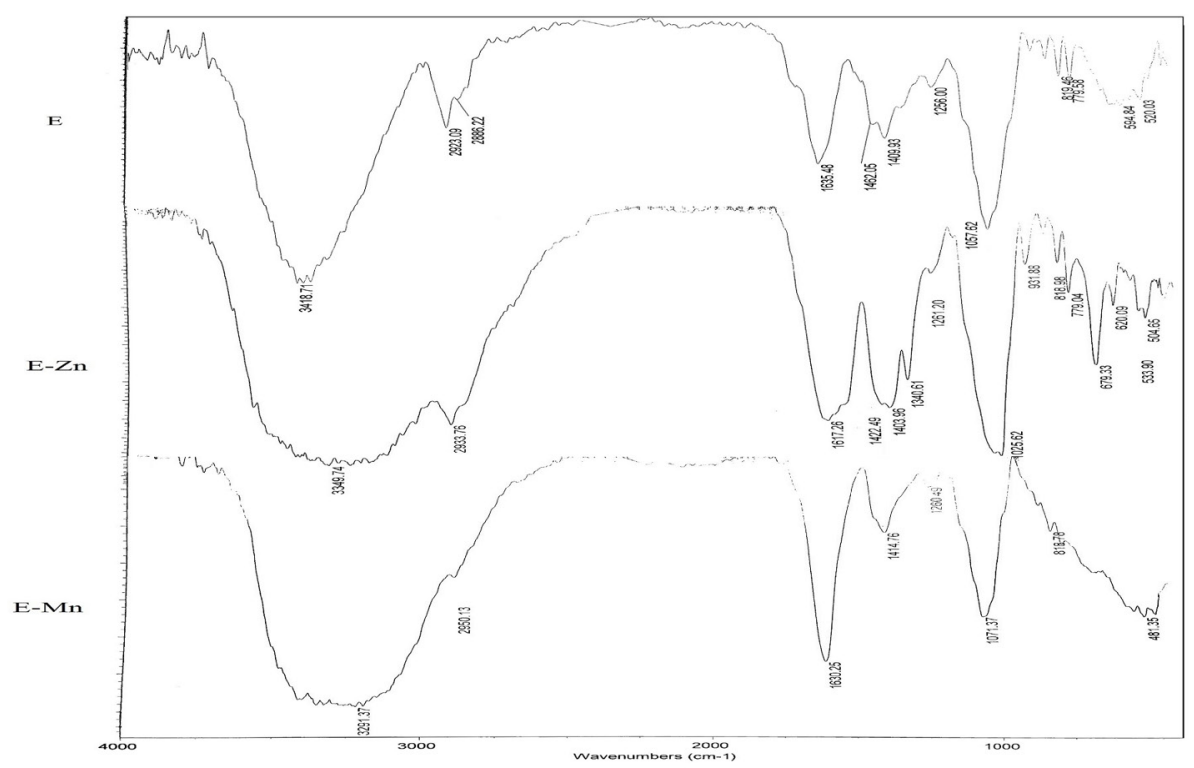

Fig. 1. FT-IR spectra of absolute ethanol extract (E and its complexes with $\mathrm{Zn}(\mathrm{E}-\mathrm{Zn})$ and $\mathrm{Mn}(\mathrm{E}-\mathrm{Mn})$ 


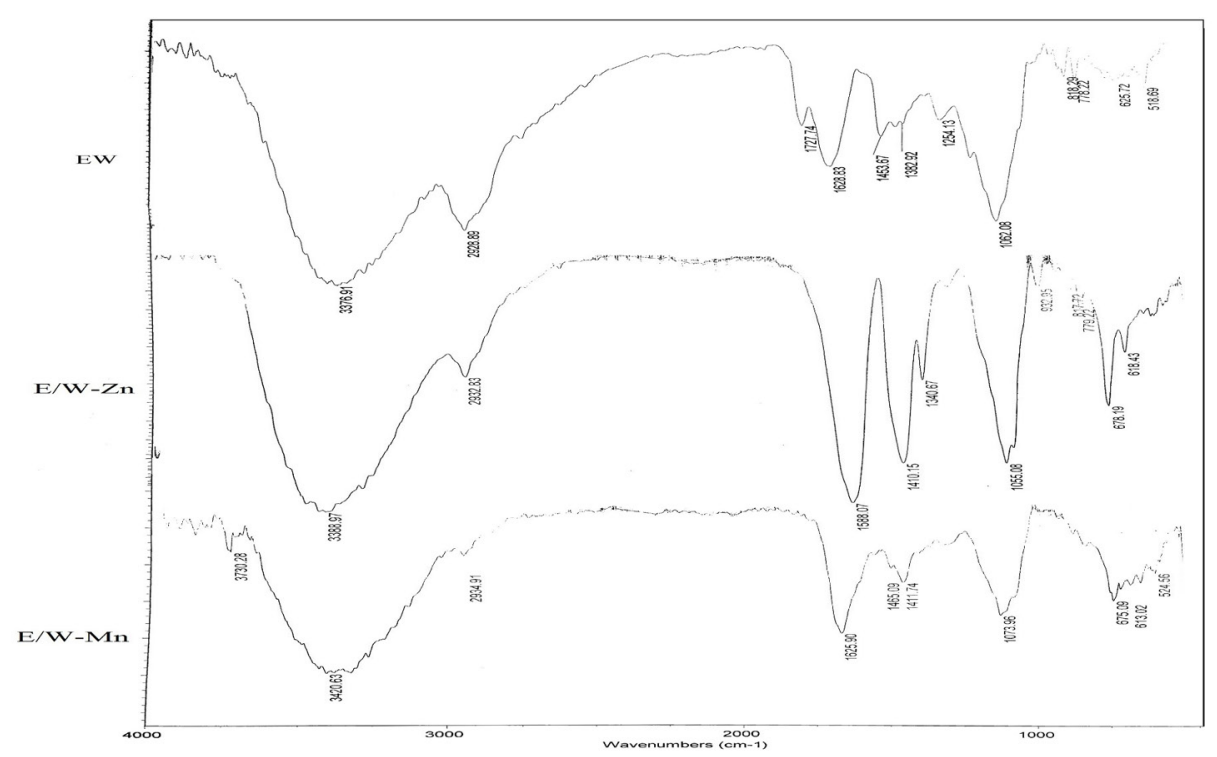

Fig. 2. FT-IR spectra of ethanol (70\%) extract (E/W) and its complexes with Zn (E/W-Zn) and $\mathrm{Mn}(\mathrm{E} / \mathrm{W}-\mathrm{Mn})$

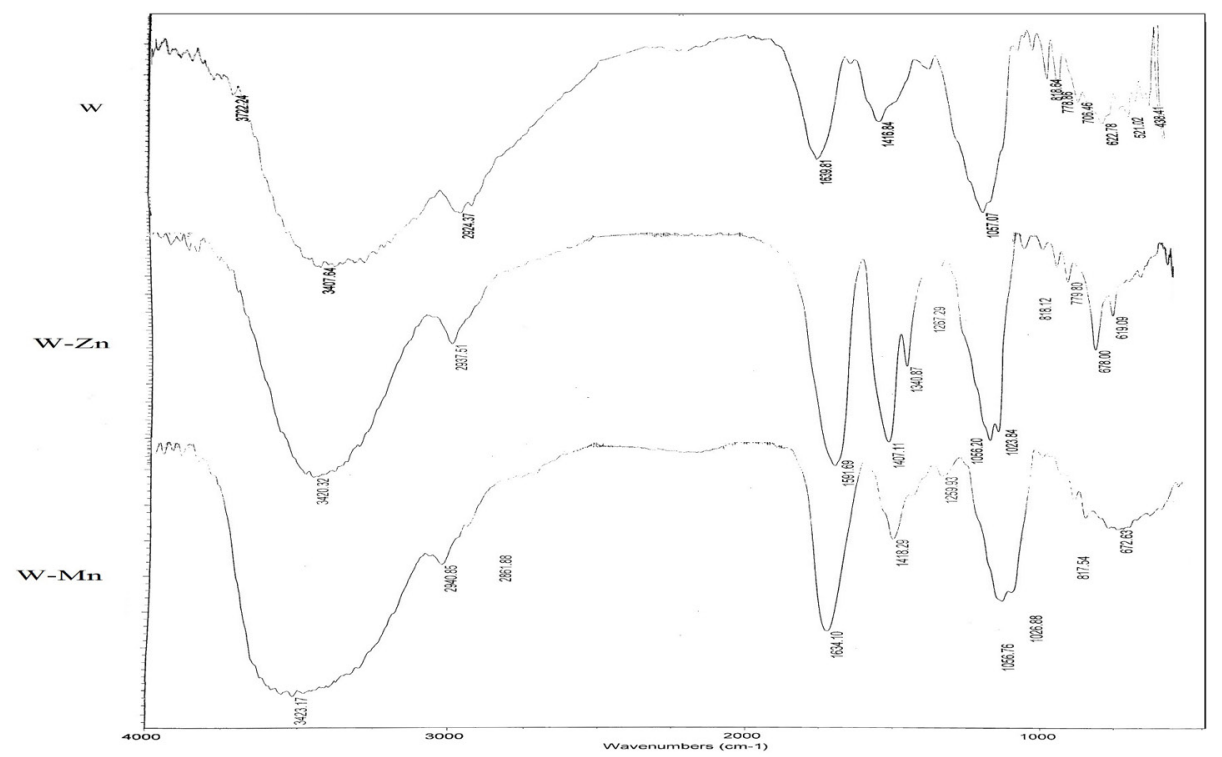

Fig. 3. FT-IR spectra of water (W) extract and its complexes with $\mathrm{Zn}(\mathrm{W}-\mathrm{Zn})$ and $\mathrm{Mn}$ (W-Mn)

In the extracts, the bands in the $1635-1730 \mathrm{~cm}^{-1}$ region could be related to $\mathrm{C}=\mathrm{C}$ stretching vibration of aromatic rings and $\mathrm{C}=\mathrm{O}$ in flavonoid structure. In the IR spectra of $\mathrm{Zn}$ complexes of the extracts, the absorption band of $v(\mathrm{C}=\mathrm{C}$ and $\mathrm{C}=\mathrm{O})$ significantly shifted to a lower frequency (around 1588-1630 $\mathrm{cm}^{-1}$ ). This result could be due to the coordination of the $\mathrm{C}=\mathrm{O}$ group to the metal ion (Priya et al., 2015), and 

ursinum extracts and their metal complexes. Acta Sci. Pol. Technol. Aliment., 17(3), 219-226. http://dx.doi.org/10.17306/J. AFS.2018.0585

Table 1. FT-IR spectrum data of the extracts and metal complexes

\begin{tabular}{lccccc}
\hline \multicolumn{1}{c}{ Sample } & $v(\mathrm{O}-\mathrm{H})$ & $v(\mathrm{C}=\mathrm{O})$ and $v(\mathrm{C}=\mathrm{C})$ & $v(\mathrm{C}-\mathrm{O}-\mathrm{C})$ & $v(\mathrm{Zn}=\mathrm{O})$ & $v(\mathrm{Mn}=\mathrm{O})$ \\
\hline W & $3000-3700$ & $1417-1640$ & 1264 & - & - \\
W-Zn & $3000-3700$ & $1407-1591$ & 1267 & - & - \\
W-Mn & $3000-3700$ & $1418-1634$ & 1259 & - & - \\
EW & $3000-3500$ & $1453-1727$ & 1254 & 678 & - \\
EW-Zn & $3000-3700$ & $1410-1588$ & 1255 & - & - \\
EW-Mn & $3000-3700$ & $1411-1625$ & 1266 & - \\
E & $3000-3500$ & $1410-1635$ & 1256 & 679 & - \\
E-Zn & $3000-3700$ & $1403-1617$ & 1261 & - \\
E-Mn & $3000-3700$ & $1414-1630$ & 1260 & - \\
\hline
\end{tabular}

E - absolute ethanol extract. E/W - ethanol (70\%) extract. W - water extract.

formation of a new ring that increases the conjugative effect. The moderate bands at $1382-1462 \mathrm{~cm}^{-1}$ in the IR spectrum of the extracts could be related to flavonoids and aromatic rings that significantly became strong and shifted to a higher frequency in the IR spectra of $\mathrm{Zn}$-complexes of the extracts. In addition, in the extracts, the band at $1250-1260 \mathrm{~cm}^{-1}$ would be due to stretching vibration of $\mathrm{C}-\mathrm{O}-\mathrm{C}$ group in carbohydrates and flavonoids. This band in the metal complexes of the extracts shifted little (lower or higher frequency), suggesting the metal reactions were affected indirectly in the electronic charge distribution of the molecules that contributed to the complex formation.

The IR spectrum of the $\mathrm{Zn}$ - and Mn-complexes revealed a moderate band at 670 to $680 \mathrm{~cm}^{-1}$ which is not presented in the extracts. This vibration indicates the interaction between metal ions and oxygen atoms (O-Zn and O-Mn; Zhao et al., 2010). These findings were similar to the results of FT-IR from chelating the flavonoids and phenolics with metals (II) that were reported by previous studies (Kalinowska et al., 2016). As the flavonol derivatives are the most common polyphenolic compounds found in A. ursinum, the hypothesis that flavonol derivatives are one of the main groups interacting with $\mathrm{Zn}(\mathrm{II})$ and $\mathrm{Mn}(\mathrm{II})$ could be viable, although it is doubtful for the Mn-complexes.

\section{Total phenolic content and antioxidant activity}

The total phenolic contents were expressed as mg gallic acid equivalents per weight of fresh leaves.
The $70 \%$ ethanol and water extracts showed significantly $(p<0.05)$ more phenolic content compared to ethanol extract. According to the results, there was no significant $(p<0.05)$ difference between the total phenol content of $70 \%$ ethanol $(1115.0 \pm 101.1 \mathrm{mg}$ $\mathrm{GAE} / 100 \mathrm{~g}$ ) and water $915.0 \pm 81.7 \mathrm{mg} \mathrm{GAE} / 100 \mathrm{~g}$ ) extracts (Table 2). On the other hand, water extract was found to have the highest DPPH radical scavenging activity $\left(\mathrm{SC}_{50}=0.471 \mathrm{mg} / \mathrm{mL}\right)$. This is probably due to the presence of more polar (poly) phenolic compounds with stronger antioxidant activity in this extract. The SC50 of ascorbic acid as a positive standard was 0.008 $\mu / \mathrm{mL}$. Moreover, the antioxidant activity of the metal complexes was significantly lower $\left(\mathrm{SC}_{50}>1 \mathrm{mg} / \mathrm{mL}\right)$ in comparison with the extracts (Table 2). This may be related to the reduction in the possibility of hydrogen donation from hydroxyl groups of polyphenols (Dolatabadi et al., 2014) or it may be due to the inability of more bulky metal-complexes to react with DPPH radicals (Prior et al., 2005). These results confirmed that the extraction solvent affects the phenolic content and radical scavenging activity of $A$. ursinum.

\section{Anti-tyrosinase activity}

The tyrosinase inhibitory activities of the extracts and their metal complexes are compared in Table 2. In the concentration range tested, enzyme inhibitory activity was directly related to the sample concentration. Despite having less antioxidant effect, the $70 \%$ ethanol extract showed higher anti-tyrosinase activity 
Nikkhahi, M., Souri, E., Sarkhail, P., Baeeri, M., Mohammadhosseini, N. (2018). Evaluation of anti-tyrosinase activity of Allium ursinum extracts and their metal complexes. Acta Sci. Pol. Technol. Aliment., 17(3), 219-226. http://dx.doi.org/10.17306/J. AFS.2018.0585

Table 2. Total phenolic content [mg GAE/100 g FW], DPPH radical scavenging $\left(\mathrm{SC}_{50}\right)$ and anti-tyrosinase activity $\left(\mathrm{IC}_{50}\right)$ of the samples

\begin{tabular}{|c|c|c|c|c|c|c|c|c|c|}
\hline Sample & $\mathrm{E}$ & $\mathrm{E}-\mathrm{Zn}$ & E-Mn & $\mathrm{E} / \mathrm{W}$ & E/W-Zn & E/W-Mn & W & W-Zn & W-Mn \\
\hline $\begin{array}{l}\text { Total phenolic content } \\
\text { mg GAE/100 g FW }\end{array}$ & $507.0 \pm 46.4$ & - & - & $1115 \pm 101.1$ & - & - & $915.7 \pm 81.7$ & - & - \\
\hline $\begin{array}{l}\text { DPPH scavenging } \\
\mathrm{SC}_{50}, \mathrm{mg} / \mathrm{mL}\end{array}$ & 0.643 & $>1$ & $>1$ & 0.532 & $>1$ & $>1$ & 0.471 & $>1$ & $>1$ \\
\hline $\begin{array}{l}\text { Antityrosinase activity } \\
\mathrm{IC}_{50}, \mathrm{mg} / \mathrm{mL}\end{array}$ & 0.460 & 0.505 & 0.402 & 0.392 & 0.496 & 0.462 & 0.506 & 0.482 & 0.414 \\
\hline
\end{tabular}

E - absolute ethanol extract. E/W - ethanol (70\%) extract. W - water extract.

$\left(\mathrm{IC}_{50}=0.392 \mathrm{mg} / \mathrm{mL}\right)$ in comparison with the two other ones. Kojic acid as a positive control indicated an $\mathrm{IC}_{50}$ value of $0.031 \mathrm{mg} / \mathrm{mL}$. Among the metal complex extracts, only manganese complexes of the water and $100 \%$ ethanol extracts exhibited a higher tyrosinase inhibitory effect $\left(\mathrm{IC}_{50}=0.414\right.$ and $0.402 \mathrm{mg} / \mathrm{mL}$ respectively) than their related extracts. This result may be because of a different molecular configuration and altering the affinity of phenolics to the tyrosinase (Chang, 2009).

\section{CONCLUSION}

The antioxidant and anti-tyrosinase activity of different $A$. ursinum extracts and their metal complexes were evaluated using DPPH radical scavenging assay and mushroom tyrosinase assay, respectively, to find a new anti-browning and whitening agent, which is of great interest to the food industry and pharmaceutical applications. The results showed that the polarity of extracting solvents and the solubility of the phenolic compounds in the solvents had a noticeable influence on the yield, phenolic content, antioxidant and antityrosinase activity. By considering both yield and phenolic content, extracting by use of $70 \%$ ethanol and $100 \%$ water provided significantly better results than the $100 \%$ ethanol solvent system. But despite the similar values of total phenolic contents, water extract of A. ursinum showed the highest DPPH radical scavenging activity $\left(\mathrm{SC}_{50}=0.471 \mathrm{mg} / \mathrm{mL}\right)$ and $70 \%$ ethanol showed the highest tyrosinase inhibitory effect $\left(\mathrm{IC}_{50}\right.$ value of $0.392 \mathrm{mg} / \mathrm{mL}$ ) in comparison to other solvent systems. However, the results proved that $\mathrm{Zn}$ and Mn complexes of these three different extracts from A. ursinum had no significant effect on DPPH radical scavenging activity. In contrast to the findings of $\mathrm{Zn}$ -complexes of the extracts, the manganese complex of A. ursinum extracts, based on solvent extraction, could increase the tyrosinase inhibition activity and could be a good candidate for food additives and cosmetic applications.

\section{REFERENCES}

Bazzaz, B. S. F., Azadbakht, M., Doust, M. S. (2008). Antibacterial activity of essential oils of Iranian plants (Mazandaran province). J. Essent. Oil Bear Plants, 11(4), 436-442. https://doi.org/10.1080/0972060X.2008.10 643651

Briganti, S., Camera, E., Picardo, M. (2003). Chemical and instrumental approaches to treat hyperpigmentation. Pigment. Cell Res., 16(2), 101-110. https://doi.org/10.1034/ j.1600-0749.2003.00029.x

Bukhari, S. B., Memon, S., Mahroof-Tahir, M., Bhanger, M. I. (2009). Synthesis, characterization and antioxidant activity copper-quercetin complex. Spectrochim. Acta Mol. Biomol. Spectrosc., 71(5), 1901-1906. https://doi. org/10.1016/j.saa.2008.07.030

Chang, T.-S. (2009). An updated review of tyrosinase inhibitors. Int. J. Mol. Sci., 10(6), 2440-2475. https://doi. org/10.3390/ijms10062440

Chudzik, B., Malm, A., Rajtar, B., Kolodziej, S., Polz-Dacewicz, M. A. (2010). The fresh extracts of Allium species as potential in vitro agents against planktonic and adherent cells of Candida spp. Ann. Univ. Mariae CurieSklodowska, DDD Pharm., 23(1), 73-78. 
Dolatabadi, J. E. N., Mokhtarzadeh, A., Ghareghoran, S. M., Dehghan, G. (2014). Synthesis, characterization and antioxidant property of quercetin- $\mathrm{Tb}(\mathrm{III})$ complex. Adv. Pharm. Bull., 4(2), 101-104. https://doi.org/10.5681/ apb.2014.016

Figueiras Abdala, A., Mendoza, N., Valadez Bustos, N., Escamilla Silva, E. M. (2017). Antioxidant capacity analysis of blackberry extracts with different phytochemical compositions and optimization of their ultrasound assisted extraction. Plant. Foods Hum. Nutr., 72(3), 258 265. https://doi.org/10.1007/s11130-017-0616-3

Kalinowska, M., Świderski, G., Matejczyk, M., Lewandowski, W. (2016). Spectroscopic, thermogravimetric and biological studies of $\mathrm{Na}(\mathrm{I}), \mathrm{Ni}(\mathrm{II})$ and $\mathrm{Zn}$ (II) complexes of quercetin. J. Therm. Anal. Calorim., 126(1), 141-148. https://doi.org/10.1007/s10973-016-5362-5

Kasprzak, M. M., Erxleben, A., Ochocki, J. (2015). Properties and applications offlavonoid metal complexes. RSCAdv., 5(57), 45853-45877. https://doi.org/10.1039/C5RA05 069C

Kim, Y.-J. (2007). Antimelanogenic and antioxidant properties of gallic acid. Biol. Pharm. Bull., 30(6), 1052-1055. https://doi.org/10.1039/C5RA05069C

Kumar, S., Pandey, A. K. (2013). Chemistry and biological activities of flavonoids: an overview. Sci. World J., ID: 162750. http://dx.doi.org/10.1155/2013/162750

Lachowicz, S., Kolniak-Ostek, J., Oszmiański, J., Wiśniewski, R. (2017). Comparison of phenolic content and antioxidant capacity of bear garlic (Allium ursinum L.) in different maturity stages. J. Food Process Preserve., 41(1), e12921. https://doi.org/10.1111/jfpp.12921

Li, C. Y., Lee, E. J., Wu, T. S. (2004). Antityrosinase principles and constituents of the petals of Crocus sativus. J. Nat. Prod., 67(3), 437-440. https://doi.org/10.1021/np 0302854

Nickavar, B., Yousefian, N. (2009). Inhibitory effects of six Allium species on alpha-amylase enzyme activity. Iran J. Pharm. Res., 8(1), 53-57.

Oszmiański, J., Kolniak-Ostek, J., Wojdyło, A. (2013). Characterization and content of flavonol derivatives of Allium ursinum L. plant. J. Agric. Food Chem., 61, 176184. https://doi.org/10.1021/jf304268e

Prior, R. L., Wu, X., Schaich, K. (2005). Standardized methods for the determination of antioxidant capacity and phenolics in foods and dietary supplements. J. Agric. Food Chem., 53(10), 4290-4302. https://doi.org/10.1021/jf05 02698

Priya, S. R., Balachandran, S., Daisy, J., Mohanan, V. P. (2015). Reactive centers of curcumin and the possible role of metal complexes of curcumin as antioxidants. Univ. J. Phys. Appl., 9(1), 6-16. https://doi.org/10.13189/ujpa. 2015.030102

Rho, H. S., Ghimeray, A. K., Yoo, D. S., Ahn, S. M., Kwon, S. S., Lee, K. H., ..., Cho, J. Y. (2011). Kaempferol and kaempferol rhamnosides with depigmenting and antiinflammatory properties. Molecules, 16, 3338-3344. https://doi.org/10.3390/molecules16043338

Saewan, N., Koysomboon, S., Chantrapromma, K. (2011). Anti-tyrosinase and anti-cancer activities of flavonoids from Blumea balsamifera DC. J. Med. Plants Res., 5(6), 1018-1025.

Saewan, N., Thakam, A., Jintaisong, A., Kittigowitana, K. (2014). Anti-tyrosinase and cytotoxicity activities of curcumin-metal complexes. Int. J. Pharm. Pharm. Sci., 6(10), 270-273.

Sarkhail, P., Salimi, M., Sarkheil, P., Heidarnezhad, F., Saeidnia, S. (2017). Evaluation of anti-melanogenic and cytotoxic activities of Phlomis caucasica on human melanoma SKMEL-3 cells. Int. J. Cancer Manag., 10(3), e4633. https://doi.org/10.5812/ijcm.463

Sobolewska, D., Podolak, I., Makowska-Wąs, J. (2015). Allium ursinum: botanical, phytochemical and pharmacological overview. Phytochem. Rev., 14(1), 81-97. https://doi.org/10.1007/s11101-013-9334-0

Souza de, R. F., Giovani de, W. F. (2005). Synthesis, spectral and electrochemical properties of $\mathrm{Al}$ (III) and $\mathrm{Zn}$ (II) complexes with flavonoids. Spectrochim. Acta Mol. Biomol. Spectrosc., 61(9), 1985-1990. https://doi.org/10. 1016/j.saa.2004.07.029

Symonowicz, M., Kolanek, M. (2012). Flavonoids and their properties to form chelate complexes. Biotechnol. Food Sci., 76(1), 35-41.

Thakam, A., Saewan, N. (2011). Antioxidant activities of curcumin-metal complexes. Thai. J. Agric. Sci., 44(5), 188-193.

Vlase, L., Parvu, M., Parvu, E. A., Toiu, A. (2013). Phytochemical analysis of Allium fistulosum L. and A. ursinum L. Dig. J. Nanomater. Biostruct. (DJNB), 8(1), 457-467. Zhao, X. Z., Jiang, T., Wang, L., Yang, H., Zhang, S., Zhou, P. (2010). Interaction of curcumin with $\mathrm{Zn}$ (II) and $\mathrm{Cu}(\mathrm{II})$ ions based on experiment and theoretical calculation. J. Mol. Struct., 984(1-3), 316-325. https://doi.org/10. 1016/j.molstruc.2010.09.049

Zhou, J., Wang, L.-fang, Wang, J.-yi, Tang, N. (2001). Synthesis, characterization, antioxidative and antitumor activities of solid quercetin rare earth (III) complexes. J. Inorg. Biochem., 83, 41-48. https://doi.org/10.1016/ S0162-0134(00)00128-8 